\title{
Influence of anthropometric measures and socio-demographic factors on menstrual pain and irregular menstrual cycles among university students in Bangladesh
}

\author{
Md. Golam Hossain ${ }^{1 *}$, Md. SABIRUZZAMAN², Saima IsLAM ${ }^{3}$, Raja Zyroul HisYAM${ }^{1}$, \\ Pete E. LeSTREL ${ }^{4}$, Tunku KAMARUL ${ }^{1}$ \\ ${ }^{1}$ National Orthopaedic Centre of Excellence for Research and Learning, Department of Orthopaedic Surgery, University of Malaya, \\ Kuala Lumpur 50603, Malaysia \\ ${ }^{2}$ Institute of Mathematical Sciences, University of Malaya, Kuala Lumpur 50603, Malaysia \\ ${ }^{3}$ Department of Statistics, University of Rajshahi, Rajshahi 6205, Bangladesh \\ ${ }^{4}$ Sections of Orthodontics and Oral Biology, School of Dentistry, University of California, Los Angeles, CA 90024-1668, USA
}

Received 3 September 2010; accepted 7 December 2010

\begin{abstract}
Menstrual disturbances generally affect the daily activities of young females. The aim of this study was to determine the effects of anthropometric measures and sociodemographic factors on menstrual disturbances among university students in Bangladesh. Data were collected from 995 students from Rajshahi University using a stratified sampling technique between July 2004 and May 2005. Factors influencing menstrual pain and irregular menstrual cycles were examined with multiple logistic regression analysis. Stepwise logistic regression analysis was also used to determine the most influential factors affecting menstrual disturbances. The prevalence of menstrual pain among the university students studied was very high $(72.3 \%)$, while the experience of irregular menstrual cycles was very low $(12.9 \%)$. Multiple logistic regressions demonstrated that menstrual pain was affected by early age at menarche, early birth order, longer length of menstrual flow and high family income. Students suffering from irregular menstrual cycles displayed a delay in menarche, longer duration of menstrual flow and larger body mass index (BMI) values. Moreover, stepwise logistic regression showed that age at menarche, birth order, duration of menstrual flow and family income were the most important factors influencing menstrual pain. Age at menarche, duration of menstrual flow and BMI were found to be the most important factors affecting irregular menstrual cycles. These results suggest that age at menarche and duration of menstrual flow are significant common factors which affect menstrual pain and irregular menstrual cycles. Consequently, menstrual disturbance can be considered as one of the major health problems of Bangladeshi university female students and requires attention.
\end{abstract}

Key words: Menstrual disturbance, university students, Bangladesh, logistic regression

\section{Introduction}

Before or during their menstrual period some females suffer pain. This pain usually begins a day or two before the menstrual flow, and may continue through the first two days of menstruation. Menstrual pain usually affects young women in their teens and early twenties. Many young adult females suffer menstrual pain and menstrual fever and their daily activities are often adversely affected (Agarwal and Venkat, 2009). Dysmenorrhea (menstrual pain) is reflected by problems such as pain in the legs and back, headaches, nausea and diarrhea. As a consequence, menstrual pain affects class absenteeism, and places limitations on social, ac-

* Correspondence to: Md. Golam Hossain, Department of Orthopaedic Surgery, Faculty of Medicine, University of Malaya, Lembah Pantai, Kuala Lumpur 50603, Malaysia.

E-mail: hossain95@yahoo.com

Published online 19 February 2011

in J-STAGE (www.jstage.jst.go.jp) DOI: 10.1537/ase.100903 ademic and sporting activities. Menstrual disorder (irregular menstrual cycles) is another serious menstrual problem that interferes with the normal menstrual cycles, causing pain, unusually heavy or light bleeding, delayed menarche or missed periods. Irregular menstrual cycles and irregular menstrual bleeding lead to increased risk of hip fracture (Nicodemus et al., 2001).

Menstruation disturbances of young adults have been found worldwide (Montero et al., 1996; Nicodemus et al., 2001; Hirata et al., 2002; Weller and Weller, 2002; Adams and Deitch, 2005; El-Gilany et al., 2005; Järvelaid, 2005; Anastasakis et al., 2008; Jahromi et al., 2008; Loto et al., 2008; Singh et al., 2008; Agarwal and Venkat, 2009; Chang and Chen, 2009; Farquhar et al., 2009; Ogunfowokan and Babatunde, 2010; Ozerdogan et al., 2009; Polat et al., 2009; Yamamoto et al., 2009; etc.).

With respect to Bangladeshi populations, researchers have studied menstruation among Bangladeshi females, and have tried to find the relationship between age at menarche and nutritional status, post-menarcheal growth, marriage, 
anthropometric measures and sociodemographic factors (Chowdhury et al., 1977; Ogata, 1979; Haq, 1984; Riley et al., 1989; Chowdhury et al., 2000; Hossain et al., 2010). To the best of our knowledge, no previous studies on menstrual disturbance among Bangladeshi females are available.

The aim of the present study was to try to establish the effects of anthropometric measures and sociodemographic factors on menstrual disturbances (menstrual pain and irregular menstrual cycles) of female university students in Bangladesh.

\section{Materials and Methods}

The study sample consisted of 995 healthy Bangladeshi adult students residing in student halls at the University of Rajshahi, Bangladesh, between July 2004 and May 2005. Ages at the time of measurement ranged from 18 to 25 years (average age 19.29; standard deviation 0.97 years). The university has four female halls of residence, accommodating a total of 2900 students at any particular time. The University of Rajshahi is the second largest university in Bangladesh, with students coming from all over the country. The sample was selected using stratified random sampling with a proportional allocation technique. This study was done with the permission from the authority of the University of Rajshahi and all subjects gave their consent.

Selected students $(n=1000)$ were initially asked by one of the (female) authors (S.I.), using a standard questionnaire, to report their age at menarche, menstrual disturbances and sociodemographic characteristics, which were recorded for each subject. Five students who could not remember their menarcheal age were excluded from the current analysis. Consequently, 995 female students were included in this study. Body height was measured as the distance from the top of the head in the midsagittal plane to the floor using an anthropometer, and body weight was taken with thin clothing using weighing scales. All measurements were done by a single researcher (S.I.). Body mass index (BMI), defined as the ratio of weight in kilograms to height squared (in meters), was calculated.

Menstrual pain was reported as acute spasmodic pain, experienced in the lower abdomen, usually beginning a day or two before menstrual flow, and continuing through the first two days of menstruation. The period between the first day of menstrual bleeding and the day immediately prior to the next menstrual bleeding was defined as the menstrual cycle. While it has often been stated that a regular period occurs every 28 days, in actuality every woman's period of menstrual cycle is different. In this study the normal period ranged between 25 to 31 days from the beginning of period to the next period. Thus, an irregular menstrual cycle was defined as less than 25 days or more than 31 days from first menstrual flow to next. Irregular menstrual cycles were reported as a part of the questionnaire history of menstrual cycles as experienced by the students.

Multiple logistic regression analysis was utilized to examine the association between the menstrual disturbances (pain and irregular menstrual cycles) with anthropometric measures and sociodemographic factors. Menstrual pain and menstrual cycles were used separately as dependent vari- ables. The underlying multiple logistic regression model corresponding to each variable is:

$$
\begin{aligned}
\log [P /(1-P)]= & \beta_{0}+\beta_{1} X_{1}+\beta_{2} X_{2}+\beta_{3} X_{3}+\beta_{4} X_{4} \\
& +\beta_{5} X_{5}+\beta_{6} X_{6}+\beta_{7} X_{7}+\beta_{8} X_{8}+\beta_{9} X_{9} \\
& +\beta_{10} X_{10}
\end{aligned}
$$

where $P=$ the probability of menstrual pain (coded 1$)$, or irregular menstrual cycles (coded 1$)$

$$
\begin{aligned}
& \begin{aligned}
1-P= & \text { the probability of non-menstrual pain (coded } 0), \\
& \text { or regular menstrual cycles (coded } 0)
\end{aligned} \\
& X_{1}=\text { height }(\mathrm{cm}) \\
& X_{2}=\text { age at menarche } \\
& X_{3}=\text { BMI }\left(\mathrm{kg} /(\mathrm{m})^{2}\right) \\
& X_{4}=\text { menstrual cycles }(1 \text { if irregular, } 0 \text { if regular), when } \\
& \text { menstrual pain is the response variable } \\
& X_{4}= \text { menstrual pain }(1 \text { if pain, } 0 \text { if no pain), when men- } \\
& \text { strual cycles is the response variable } \\
& X_{5}= \text { religion }(1 \text { if Muslim, } 0 \text { if others }) \\
& X_{6}= \text { duration of menstrual flow }(1 \text { if } \geq 8 \text { days, } 0 \text { if } 3-7 \\
& \text { days) } \\
& X_{7}= \text { birth order } \\
& X_{8}= \text { number of siblings } \\
& X_{9}= \text { marital status }(1 \text { if unmarried, } 0 \text { if married) } \\
& X_{10}= \text { monthly family income (in Taka) } \\
& \beta_{0}= \text { intercept term, and }
\end{aligned}
$$

$\beta_{i}=$ unknown logistic regression coefficients $(i=1,2,3, \ldots$, 10). The parameter $\beta_{i}$ refers to the effect of $X_{i}$ on the log odds such that $Y=1$, controlling the other $X_{i}$. There is an important assumption in multiple regression, either linear or logistic, that there is no multicollinearity problem (dependent each to other) among the independent variables. However, there is no exact method to detect the multicollinearity problem in multiple logistic regression analysis. In this study the magnitude of the standard error (SE) was used to detect the multicollinearity problem, if the magnitude of the SE lies between 0.001 and 0.5 , it is judged that there is no evidence of multicollinearity (Chan, 2004).

Finally, stepwise logistic regression analysis was used to choose the most influential variables for menstrual pain and irregular menstrual cycles. Stepwise logistic regression analysis is a technique for selecting influential variables in multiple regression models (Chatterjee and Hadi, 2006). In stepwise logistic regression analysis both methods, forward LR and backward LR, compute the final step by subsequently adding (forward LR) or taking away (backward LR) variables. Both methods stop the iterative process once a process step is reached which no longer improves results significantly compared to the last step taken. Backward elimination may have the advantage that it will take into consideration suppressor effects that might be lost in forward inclusion (Menard, 2002). The backward elimination procedure starts with the full equation and successively drops one variable at a time. The variables are dropped on the basis of their contribution to the reduction of error sum of squares. The contribution of individual variable for each step was checked by the Wald statistic. If all the Wald test values are significant, the full set of variables is retained in 
the final step. Statistical significance was accepted at $P<0.05$. Statistical analyses were carried out using SPSS software (version 15.0).

\section{Results}

A total of 995 female students were interviewed and examined. Menstrual pain and irregular menstrual cycle were reported by $72.3 \%$ and $12.9 \%$ of respondents, respectively. Approximately $97 \%$ of students reported a duration of menstrual flow within the 3-7 day range. A majority of students were unmarried (92.8\%) and Muslim (89.4\%) (Table 1).

Table 2 shows the mean difference in height, weight, BMI, age at menarche, monthly family income, number of siblings and birth order between menstrual pain and nonmenstrual pain groups, and between irregular and regular menstrual cycle groups. The age at menarche of the menstrual pain group was significantly $(P<0.01)$ lower than that of the non-menstrual pain students. The monthly family income of female students who had menstrual pain was significantly $(P<0.05)$ higher than that of the non-menstrual pain group. The birth order of the menstrual pain group students who was earlier $(P<0.05)$ than that of the students that did not
Table 1. Frequency distribution of menstrual pain, irregular menstrual cycles and demographic factors of university students in Bangladesh

\begin{tabular}{llccc}
\hline \multicolumn{1}{c}{ Variable } & Status & Frequency & $\begin{array}{c}\text { Percent } \\
(\%)\end{array}$ & $\begin{array}{c}\text { Cumulative } \\
\text { Percent }\end{array}$ \\
\hline Menstrual pain & Yes & 719 & 72.30 & 72.30 \\
& No & 276 & 27.70 & 100.0 \\
\hline Menstrual cycles & Irregular & 128 & 12.90 & 12.90 \\
& Regular & 867 & 87.10 & 100.0 \\
\hline Residence & Urban & 478 & 48 & 48 \\
& Rural & 517 & 52 & 100 \\
\hline Duration of & $\leq 2$ days & 0 & 0 & 0 \\
menstrual flow & 3-7 days & 963 & 96.8 & 96.8 \\
& $\geq 8$ days & 32 & 3.2 & 100 \\
\hline Religion & Muslim & 890 & 89.4 & 89.4 \\
& Others & 105 & 10.6 & 100 \\
\hline Marital status & Married & 72 & 7.2 & 7.2 \\
& Unmarried & 923 & 92.8 & 100 \\
\hline
\end{tabular}

Table 2. Mean differences ( $t$-test) in anthropometric measures and demographic factors for two groups: (1) menstrual pain and non-menstrual pain groups, and (2) irregular and regular menstrual cycles groups

\begin{tabular}{|c|c|c|c|c|c|c|}
\hline & & $n$ & Mean & SD & Mean difference & $P$-value \\
\hline \multicolumn{7}{|l|}{ (1) } \\
\hline Height $(\mathrm{cm})$ & $\begin{array}{l}\text { Pain } \\
\text { No pain }\end{array}$ & $\begin{array}{l}719 \\
276\end{array}$ & $\begin{array}{l}155.28 \\
155.09\end{array}$ & $\begin{array}{l}5.00 \\
4.63\end{array}$ & 0.19 & 0.292 \\
\hline Weight (kg) & $\begin{array}{l}\text { Pain } \\
\text { No pain }\end{array}$ & $\begin{array}{l}719 \\
276\end{array}$ & $\begin{array}{l}47.80 \\
47.54\end{array}$ & $\begin{array}{l}6.48 \\
6.16\end{array}$ & 0.26 & 0.283 \\
\hline Age at menarche (years) & $\begin{array}{l}\text { Pain } \\
\text { No pain }\end{array}$ & $\begin{array}{l}719 \\
276\end{array}$ & $\begin{array}{l}13.03 \\
13.35\end{array}$ & $\begin{array}{l}1.18 \\
1.03\end{array}$ & -0.32 & $0.001 * *$ \\
\hline BMI & $\begin{array}{l}\text { Pain } \\
\text { No pain }\end{array}$ & $\begin{array}{l}719 \\
276\end{array}$ & $\begin{array}{l}19.82 \\
19.77\end{array}$ & $\begin{array}{l}2.50 \\
2.49\end{array}$ & 0.05 & 0.438 \\
\hline $\begin{array}{l}\text { Monthly family income } \\
\text { (Taka) }\end{array}$ & $\begin{array}{l}\text { Pain } \\
\text { No pain }\end{array}$ & $\begin{array}{l}719 \\
276\end{array}$ & $\begin{array}{r}10040.24 \\
8650.42\end{array}$ & $\begin{array}{r}10250.30 \\
5703.83\end{array}$ & 1389.82 & $0.034^{*}$ \\
\hline Number of siblings & $\begin{array}{l}\text { Pain } \\
\text { No pain }\end{array}$ & $\begin{array}{l}719 \\
276\end{array}$ & $\begin{array}{l}3.95 \\
4.11\end{array}$ & $\begin{array}{l}1.75 \\
1.86\end{array}$ & 0.16 & 0.205 \\
\hline Birth order & $\begin{array}{l}\text { Pain } \\
\text { No pain }\end{array}$ & $\begin{array}{l}719 \\
276\end{array}$ & $\begin{array}{l}2.60 \\
2.86\end{array}$ & $\begin{array}{l}1.84 \\
1.89\end{array}$ & 0.26 & $0.048^{*}$ \\
\hline \multicolumn{7}{|l|}{ (2) } \\
\hline Height $(\mathrm{cm})$ & $\begin{array}{l}\text { Irregular } \\
\text { Regular }\end{array}$ & $\begin{array}{l}128 \\
867\end{array}$ & $\begin{array}{l}155.24 \\
155.22\end{array}$ & $\begin{array}{l}5.08 \\
4.87\end{array}$ & 0.02 & 0.483 \\
\hline Weight (kg) & $\begin{array}{l}\text { Irregular } \\
\text { Regular }\end{array}$ & $\begin{array}{l}128 \\
867\end{array}$ & $\begin{array}{l}48.53 \\
47.61\end{array}$ & $\begin{array}{l}6.56 \\
6.36\end{array}$ & 0.92 & 0.064 \\
\hline Age at menarche (years) & $\begin{array}{l}\text { Irregular } \\
\text { Regular }\end{array}$ & $\begin{array}{l}128 \\
867\end{array}$ & $\begin{array}{l}13.29 \\
13.10\end{array}$ & $\begin{array}{l}1.10 \\
1.15\end{array}$ & 0.19 & $0.039^{*}$ \\
\hline BMI & $\begin{array}{l}\text { Irregular } \\
\text { Regular }\end{array}$ & $\begin{array}{l}128 \\
867\end{array}$ & $\begin{array}{l}20.13 \\
19.76\end{array}$ & $\begin{array}{l}2.47 \\
2.49\end{array}$ & 0.37 & $0.048^{*}$ \\
\hline Number of siblings & $\begin{array}{l}\text { Irregular } \\
\text { Regular }\end{array}$ & $\begin{array}{l}128 \\
867\end{array}$ & $\begin{array}{l}4.20 \\
3.96\end{array}$ & $\begin{array}{l}1.69 \\
1.79\end{array}$ & 0.24 & 0.154 \\
\hline Birth order & $\begin{array}{l}\text { Irregular } \\
\text { Regular }\end{array}$ & $\begin{array}{l}128 \\
867\end{array}$ & $\begin{array}{l}2.75 \\
2.66\end{array}$ & $\begin{array}{l}1.77 \\
1.87\end{array}$ & 0.09 & 0.3045 \\
\hline $\begin{array}{l}\text { Monthly family income } \\
\text { (Taka) }\end{array}$ & $\begin{array}{l}\text { Irregular } \\
\text { Regular }\end{array}$ & $\begin{array}{l}128 \\
867\end{array}$ & $\begin{array}{l}9515.10 \\
9675.68\end{array}$ & $\begin{array}{l}6001.61 \\
9625.07\end{array}$ & -160.58 & 0.854 \\
\hline
\end{tabular}

** $1 \%$ level of significance; $* 5 \%$ level of significance. 
suffer menstrual pain. The other variables were not significantly different between the menstrual pain and the non-menstrual pain groups. Table 2 also shows that female students who had experienced irregular menstrual cycles reached menarche significantly $(P<0.05)$ later than students who had experienced regular menstrual cycles. The BMI of the irregular menstrual cycle group was larger $(P<0.05)$ than that of the regular group. The other variables between students who experienced irregular and regular menstrual cycles were not significant. However, the weight of students who had experienced irregular menstrual cycles was somewhat larger $(P=0.0642)$ than that of students who had experienced regular menstrual cycles.

\section{Multiple logistic regressions results for menstrual pain}

The specific multiple logistic regression model used was:

$$
\begin{aligned}
\log [(P /(1-P)]= & \beta_{0}+\beta_{1} \mathrm{HT}+\beta_{2} \mathrm{AAM}+\beta_{3} \mathrm{BMI} \\
& +\beta_{4} \mathrm{MC}+\beta_{5} \mathrm{RE}+\beta_{6} \mathrm{DMF}+\beta_{7} \mathrm{BO} \\
& +\beta_{8} \mathrm{NS}+\beta_{9} \mathrm{MS}+\beta_{10} \mathrm{MFI}
\end{aligned}
$$

where menstrual pain is the response variable and other variables were predictors.

The estimated model was:

$$
\begin{aligned}
\log [(P /(1-P)]= & 2.903+0.009 \mathrm{HT}-0.256 \mathrm{AAM} \\
& -0.014 \mathrm{BMI}-0.245 \mathrm{MC}+0.117 \mathrm{RE} \\
& +0.289 \mathrm{DMF}-0.139 \mathrm{BO}+0.073 \mathrm{NS} \\
& +0.377 \mathrm{MS}+0.009 \mathrm{MFI}
\end{aligned}
$$

The regression coefficients of the independent variables are presented in Table 3. Since the standard error of all independent variables lay between 0.001 and 0.5 , there was no evidence of a multicollinearity problem. The coefficients and odds ratio showed that age at menarche was significant at $P<0.01$ and negatively associated with menstrual pain, and those students who reached menarche earlier had a probability of having menstrual pain of $(1-0.774) \times 100$ $=22.6 \%$ higher than their counterparts. Duration of menstrual flow was positively associated $(P=0.073)$ with menstrual pain, and students who had experienced a longer duration of menstrual flow then had a probability of getting menstrual pain of $(1.335-1) \times 100=33.5 \%$ higher than their counterparts. Birth order was negatively associated
$(P<0.05)$ with menstrual pain and students with an earlier birth position had a probability of getting menstrual pain of $(1-0.870) \times 100=13 \%$ higher than their counterparts. Family income was positively associated $(P<0.05)$ with menstrual pain, and students who came from higher-income families had only a small probability of getting menstrual pain $(1.0001-1) \times 100=0.01 \%$ compared to students from lower-income families.

\section{Multiple logistic regressions results for menstrual cycles}

The specific multiple logistic regression model used was:

$$
\begin{aligned}
\log [(P /(1-P)]= & \beta_{0}+\beta_{1} \mathrm{HT}+\beta_{2} \mathrm{AAM}+\beta_{3} \mathrm{BMI} \\
& +\beta_{4} \mathrm{MP}+\beta_{5} \mathrm{RE}+\beta_{6} \mathrm{DMF}+\beta_{7} \mathrm{BO} \\
& +\beta_{8} \mathrm{NS}+\beta_{9} \mathrm{MS}+\beta_{10} \mathrm{MFI}
\end{aligned}
$$

where menstrual cycles is a response variable and other variables were predictors.

The estimated model was:

$$
\begin{aligned}
\log [(P /(1-P)]= & -6.604+0.003 \mathrm{HT}+0.191 \mathrm{AAM} \\
& +0.85 \mathrm{BMI}-0.247 \mathrm{MP}-0.320 \mathrm{RE} \\
& +0.435 \mathrm{DMF}-0.065 \mathrm{BO}+0.146 \mathrm{NS} \\
& -0.348 \mathrm{MS}+0.008 \mathrm{MFI}
\end{aligned}
$$

The regression coefficients of the independent variables are presented in Table 4. There was no evidence of the multicollinearity problem among the predictor variables, because the standard error of all variables lay between 0.001 and 0.5 . The coefficients of multiple regression analysis demonstrated that age at menarche was positively associated $(P<0.05)$ with irregular menstrual cycles and the odds ratio showed that students who reached menarche later had a probability of experiencing irregular menstrual cycles $(1.21-1) \times 100=21 \%$ higher than their counterparts. BMI was positively associated $(P<0.05)$ with irregular menstrual cycles and students who had larger BMI values had a probability of experiencing an irregular menstrual cycles $(1.088-1) \times 100=8.8 \%$ higher than their counterparts. Duration of menstrual flow was positively associated $(P<0.05)$ with irregular menstrual cycles and students who had experienced longer durations of menstrual flow had a probability of experiencing an irregular menstrual cycles $(1.545-1) \times 100=54.5 \%$ higher than their counterparts.

Table 3. Multiple logistic regression estimates for the effects of anthropometric measurements and sociodemographic factors on menstrual pain

\begin{tabular}{lcccccc}
\hline \multicolumn{1}{c}{ Variable } & Coefficients & SE & Wald & df & $P$-value & Odds ratio \\
\hline Height & 0.009 & 0.015 & 0.348 & 1 & 0.555 & 1.009 \\
Age at menarche & -0.256 & 0.067 & 14.648 & 1 & $0.001^{* *}$ & 0.774 \\
BMI & -0.014 & 0.030 & 0.223 & 1 & 0.637 & 0.986 \\
Menstrual cycle & -0.245 & 0.225 & 1.187 & 1 & 0.276 & 0.783 \\
Religion & 0.117 & 0.238 & 0.240 & 1 & 0.624 & 1.124 \\
Duration of menstrual flow & 0.289 & 0.161 & 3.217 & 1 & 0.073 & 1.335 \\
Birth order & -0.139 & 0.066 & 4.485 & 1 & $0.034^{*}$ & 0.870 \\
Number of siblings & 0.073 & 0.074 & 0.985 & 1 & 0.321 & 1.076 \\
Marital status & 0.377 & 0.305 & 1.526 & 1 & 0.217 & 1.457 \\
Family income & 0.008 & 0.009 & 4.408 & 1 & $0.036^{*}$ & 1.0001 \\
Constant & 2.903 & 2.618 & 1.230 & 1 & 0.267 & 18.238 \\
\hline
\end{tabular}

** $1 \%$ level of significance; $* 5 \%$ level of significance. 
Table 4. Multiple logistic regression estimates for the effects of anthropometric and sociodemographic factors on irregular menstrual cycles

\begin{tabular}{|c|c|c|c|c|c|c|}
\hline Variable & Coefficients & S.E & Wald & $\mathrm{df}$ & $P$-value & Odds ratio \\
\hline Height & 0.003 & 0.020 & 0.027 & 1 & 0.868 & 1.003 \\
\hline Age at menarche & 0.191 & 0.088 & 4.707 & 1 & $0.030 *$ & 1.210 \\
\hline BMI & 0.085 & 0.038 & 5.028 & 1 & $0.025 *$ & 1.088 \\
\hline Menstrual pain & -0.247 & 0.225 & 1.207 & 1 & 0.272 & 0.781 \\
\hline Religious & -0.320 & 0.354 & 0.816 & 1 & 0.366 & 0.726 \\
\hline Duration of menstrual flow & 0.435 & 0.199 & 4.755 & 1 & $0.029^{*}$ & 1.545 \\
\hline Birth order & -0.065 & 0.082 & 0.635 & 1 & 0.426 & 0.937 \\
\hline Number of siblings & 0.146 & 0.091 & 2.541 & 1 & 0.111 & 1.157 \\
\hline Material status & -0.384 & 0.416 & 0.854 & 1 & 0.355 & 0.681 \\
\hline Family income & 0.007 & 0.008 & 0.037 & 1 & 0.847 & 1.000 \\
\hline Constant & -6.604 & 3.428 & 3.713 & 1 & 0.054 & 0.001 \\
\hline
\end{tabular}

$* 5 \%$ level of significance.

\section{Stepwise logistic regression results}

Stepwise logistic regression (backward elimination) was used to find the most influential factors influencing menstrual disturbance (menstrual pain and irregular menstrual cycles). In stepwise logistic regression analysis, all variables were included in the first step for menstrual pain (Table 5). In first step, the least significant variable based on the Wald statistic was BMI and the corresponding change in -2LR was also insignificant. Hence, BMI is the variable which was excluded from the model in the second step. In the second step, religion was least significant and the change in -2LR was insignificant; therefore, this variable was excluded from the model in the third step. The other variables, i.e. height, number of siblings, menstrual cycles and marital status, were excluded from the model by repeating the same procedure. The final step included the variables age at menarche, birth order, monthly family income and duration of menstrual flow, which were statistically significant (Table 5).

Table 6 shows the summary results of stepwise logistic regression analysis, with menstrual cycle as the response variable. The stepwise logistic regression analysis showed that all variables were included in the first step. In first step, height was the least significant variable based on the Wald statistic and the corresponding change in -2LR was insignificant. Height was excluded from the model in the second step. Family income was the least significant in the second step and the change in -2LR was insignificant; the model in third step excluded family income. The other variables, i.e. birth order, marital status, religion, menstrual pain and number of siblings, were excluded from the model by repeating the same procedure. The final step included the variables age at menarche, BMI and duration of menstrual flow, which were statistically significant (Table 6).

\section{Discussion}

The present study demonstrated that menstrual pain was reported by a majority $(72.30 \%)$ of the female students, while only $12.90 \%$ of the students experienced irregular menstrual periods. Similar findings were found in Indian

Table 5. Summary of the stepwise (backward elimination) logistic regression analysis (first and final steps) for anthropometric measures and sociodemographic factors, where menstrual pain is the response variable

\begin{tabular}{|c|c|c|c|c|c|c|c|c|c|c|}
\hline \multirow{2}{*}{ Step } & \multirow{2}{*}{ Valuable } & \multirow{2}{*}{ Coefficients } & \multirow{2}{*}{ SE } & \multirow{2}{*}{ Wald } & \multirow{2}{*}{$\mathrm{df}$} & \multirow{2}{*}{$P$-value } & \multirow{2}{*}{ Odds ratio } & \multicolumn{2}{|c|}{$95 \%$ CI for odds ratio } & \multirow{2}{*}{$\begin{array}{l}\text { Change in } \\
-2 \mathrm{LR}\end{array}$} \\
\hline & & & & & & & & Lower & Upper & \\
\hline \multirow[t]{11}{*}{ Step 1} & HT & 0.009 & 0.015 & 0.348 & 1 & 0.555 & 1.009 & 0.980 & 1.039 & 0.348 \\
\hline & AAM & -0.256 & 0.067 & 14.648 & 1 & 0.000 & 0.774 & 0.679 & 0.882 & $15.13 * *$ \\
\hline & BMI & -0.014 & 0.030 & 0.223 & 1 & 0.637 & 0.986 & 0.930 & 1.045 & 0.223 \\
\hline & $\mathrm{RE}$ & 0.117 & 0.238 & 0.240 & 1 & 0.624 & 1.124 & 0.705 & 1.792 & 0.243 \\
\hline & $\mathrm{BO}$ & -0.139 & 0.066 & 4.485 & 1 & 0.034 & 0.870 & 0.765 & 0.990 & $4.571 *$ \\
\hline & NS & 0.073 & 0.074 & 0.985 & 1 & 0.321 & 1.076 & 0.931 & 1.243 & 0.996 \\
\hline & MS & 0.377 & 0.305 & 1.526 & 1 & 0.217 & 1.457 & 0.802 & 2.648 & 1.615 \\
\hline & FI & 0.0001 & 0.0001 & 4.408 & 1 & 0.036 & 1.000 & 1.000 & 1.000 & $5.674 *$ \\
\hline & DMF & 0.289 & 0.161 & 3.217 & 1 & 0.073 & 1.335 & 0.974 & 1.831 & 3.277 \\
\hline & $\mathrm{MC}$ & -0.245 & 0.225 & 1.187 & 1 & 0.276 & 0.783 & 0.504 & 1.216 & 1.221 \\
\hline & Constant & 3.192 & 2.612 & 1.494 & 1 & 0.222 & 24.348 & & & \\
\hline \multirow[t]{5}{*}{ Step 7} & AAM & -0.239 & 0.065 & 13.386 & 1 & 0.000 & 0.787 & 0.693 & 0.895 & $13.81 * *$ \\
\hline & $\mathrm{BO}$ & -0.090 & 0.041 & 4.811 & 1 & 0.028 & 0.914 & 0.843 & 0.990 & $4.749 *$ \\
\hline & FI & 0.0001 & 0.0001 & 4.192 & 1 & 0.041 & 1.000 & 1.000 & 1.000 & $5.348 *$ \\
\hline & DMF & 0.323 & 0.159 & 4.133 & 1 & 0.042 & 1.381 & 1.012 & 1.885 & $4.226^{*}$ \\
\hline & Constant & 4.036 & 0.879 & 21.091 & 1 & 0.000 & 56.576 & & & \\
\hline
\end{tabular}

$\mathrm{HT}=$ height $(\mathrm{cm}), \mathrm{AAM}=$ age at menarche, $\mathrm{BMI}=$ body mass index, $\mathrm{RE}=$ religion, $\mathrm{BO}=$ birth order, $\mathrm{NS}=$ number of siblings, $\mathrm{MA}=\mathrm{marital}$ status, $\mathrm{FI}=$ family income, $\mathrm{DMF}=$ duration of menstrual flow, $\mathrm{MC}=$ menstrual cycles.

$* * 1 \%$ level of significance; $* 5 \%$ level of significance. 
Table 6. Summary of the stepwise (backward elimination) logistic regression analysis (first and final steps) for anthropometric measures and sociodemographic factors, where menstrual cycles is the response variable

\begin{tabular}{|c|c|c|c|c|c|c|c|c|c|c|}
\hline \multirow{2}{*}{ Step } & \multirow{2}{*}{ Valuable } & \multirow{2}{*}{ Coefficients } & \multirow{2}{*}{$\mathrm{SE}$} & \multirow{2}{*}{ Wald } & \multirow{2}{*}{$\mathrm{df}$} & \multirow{2}{*}{$P$-value } & \multirow{2}{*}{ Odds ratio } & \multicolumn{2}{|c|}{$95 \%$ CI for odds ratio } & \multirow{2}{*}{$\begin{array}{l}\text { Change in } \\
-2 \mathrm{LR}\end{array}$} \\
\hline & & & & & & & & Lower & Upper & \\
\hline \multirow[t]{11}{*}{ Step 1} & HT & 0.003 & 0.020 & 0.027 & 1 & 0.868 & 1.003 & 0.965 & 1.043 & 0.027 \\
\hline & AAM & 0.191 & 0.088 & 4.707 & 1 & 0.030 & 1.210 & 1.019 & 1.438 & $4.800^{*}$ \\
\hline & BMI & 0.085 & 0.038 & 5.028 & 1 & 0.025 & 1.088 & 1.011 & 1.172 & $4.889^{*}$ \\
\hline & $\mathrm{RE}$ & -0.320 & 0.354 & 0.816 & 1 & 0.366 & 0.726 & 0.363 & 1.454 & 0.871 \\
\hline & $\mathrm{BO}$ & -0.065 & 0.082 & 0.635 & 1 & 0.426 & 0.937 & 0.799 & 1.100 & 0.630 \\
\hline & NS & 0.146 & 0.091 & 2.541 & 1 & 0.111 & 1.157 & 0.967 & 1.384 & 2.481 \\
\hline & MS & -0.384 & 0.416 & 0.854 & 1 & 0.355 & 0.681 & 0.301 & 1.538 & 0.930 \\
\hline & MFI & 0.000 & 0.000 & 0.037 & 1 & 0.847 & 1.000 & 1.000 & 1.000 & 0.038 \\
\hline & DMF & 0.435 & 0.199 & 4.755 & 1 & 0.029 & 1.545 & 1.045 & 2.284 & $4.658^{*}$ \\
\hline & MP & -0.247 & 0.225 & 1.207 & 1 & 0.272 & 0.781 & 0.503 & 1.213 & 1.243 \\
\hline & Constant & -7.039 & 3.426 & 4.222 & 1 & 0.040 & 0.001 & & & \\
\hline \multirow[t]{4}{*}{ Step 8} & AAM & 0.182 & 0.086 & 4.477 & 1 & 0.034 & 1.200 & 1.014 & 1.421 & $4.571 *$ \\
\hline & BMI & 0.079 & 0.037 & 4.467 & 1 & 0.035 & 1.082 & 1.006 & 1.164 & $4.343^{*}$ \\
\hline & DMF & 0.467 & 0.197 & 5.632 & 1 & 0.018 & 1.595 & 1.085 & 2.345 & $5.502 *$ \\
\hline & Constant & -6.054 & 1.488 & 16.562 & 1 & 0.000 & 0.002 & & & \\
\hline
\end{tabular}

$\mathrm{MP}=$ menstrual pain; others abbreviations as Table 5 .

medical college students, where the prevalence of menstrual pain was $73.83 \%$ and the experience of irregular menstrual flow was only $7.47 \%$ (Singh et al., 2008). In this study the duration of menstrual flow also was found to be normal (37 days) for most of the students $(96.8 \%)$.

\section{Menstrual pain}

Multiple logistic regression analysis was used to find the effect of anthropometric measures, age at menarche and sociodemographic factors on menstrual disturbance. Stepwise logistic regression analysis was used to detect the major factors influencing menstrual disturbance. The coefficient of multiple logistic regression analysis showed that age at menarche was negatively associated $(P<0.001)$ with menstrual pain and that the odds ratio demonstrated that the earlier a student reached menarche, the more likely she was to have menstrual pain. This result is in agreement with that of Yamamoto et al. (2009), who reported that the age at menarche and menstrual pain of Japanese college female students was negatively associated. This relationship was also found in studies of menstrual disturbance in Sweden (Sundell et al., 1990), in Nigerian university students (Loto et al., 2008), in Italian adult females (Balbi et al., 2000) and in Spanish adolescents (Bernis et al., 1999). This study demonstrated that the duration of menstrual flow in Bangladeshi university female students was positively associated $(P=0.073)$ with menstrual pain. The odds ratio of multiple logistic regression analysis showed that the longer ( $\geq 8$ days) the duration of menstrual flow of a student, the more likely she was to experience menstrual pain. The same result was found in Italian (Balbi et al., 2000), Spanish (Bernis et al., 1999), Swiss (Sundell et al., 1990) and Nigerian studies (Loto et al., 2008). The odds ratio also demonstrated that students whose birth order was earlier and who came from a high-income family were more likely to have menstrual pain. Currently these findings cannot be corroborated with other studies. These results may reflect nutritional status: the higher the nutritional status of a student, the more likely she was to experience menstrual pain, i.e. nutritional status can have an effect on menstrual pain. At the moment this, however, is just conjecture.

Stepwise multiple regressions showed that step 7 was the best model for menstrual pain (Table 5). This final step consisted of four variables: age at menarche, birth order, family income and length of menstrual flow. The Wald statistic demonstrated that all of the predictors in the final step were significantly associated with menstrual pain. These four predictors adequately explain menstrual pain of university students in Bangladesh. To the best of our knowledge, this is the first time that stepwise logistic regression analysis has been applied to this type of study.

\section{Irregular menstrual cycles}

Irregular menstrual cycles are another serious kind of disturbance for young adult females. The coefficients of the multiple logistic regression analysis demonstrated that irregular menstrual cycles were positively associated with age at menarche, BMI and length of menstrual flow. The odds ratio showed that students who reached menarche later were more likely to experience irregular menstrual cycles. This result was in agreement with the findings of Anai et al. (2001), who found that delayed menarche was associated with irregular menstrual cycles of young Japanese adults. The odds ratio values in this study showed that students with higher BMI values were more likely to have experienced irregular menstrual cycles. This finding was supported by the finding of Wei et al. (2009), who studied menstrual disturbance of Australian women and found that both overall BMI and obesity were significantly associated with irregular menstrual cycles. This result was not in agreement with the finding of Yamamoto et al. (2009), who found that BMI was negatively associated with irregular menstrual cycles of Japanese college students. In this study, the odds ratio showed that if the duration of menstrual flow was longer ( $\geq 8$ days), the student was more likely to experience an irregular menstrual flow. This result was in agreement with the findings of 
Brooks-Gunn (1985), who found a positive relationship between the duration of menstrual flow and irregular menstrual cycles among college students in New Jersey. The same finding was found in an Italian study (Di Cintio et al., 1997).

Stepwise regression analysis showed that the final step (step 8) consisted of three variables: age at menarche, BMI and length of menstrual flow. The Wald statistic demonstrated that all three predictors in the final step were significantly associated with the presence of an irregular menstrual flow in Bangladeshi university students.

The present study suggests that early age at menarche, early birth order, longer length of menstrual flow and high family income are the main causes of menstrual pain of Bangladeshi adult students. The causes of irregular menstrual cycles are delayed age at menarche, longer duration of menstrual flow and larger BMI values. Age at menarche and duration of menstrual flow are the common factors which affect menstrual pain and irregular menstrual cycles of university students in Bangladesh. BMI is important factor affecting age at menarche. Females in Bangladesh are not generally conscious about their body weight. Consequently, they are not aware about the long-term medical issues of excess body weight causing menstrual disturbance. It may be necessary for the authorities to make the general population aware of the importance of a balanced diet and the need to make reasoned, conscious decisions about one's health. The prevalence of menstrual disturbance in university students in Bangladesh is high, and appropriate health education is needed for Bangladeshi girls during and at the end of primary school to prevent unnecessary suffering and interruption of daily activities later in life.

This study investigated the effects of some selected anthropometric measures and sociodemographic factors on menstrual disturbance. Other important factors that may be directly implicated in menstrual problems (menstrual pain and irregular menstrual cycles) are: family history of menstrual pain (Ozerdogan et al., 2009), lifestyles (Bernis et al., 1999), history of smoking (Bernis et al., 1999; Ozerdogan et al., 2009), dietary habits (Balbi et al., 2000), psychosocial stress (Yamamoto et al., 2009) and dieting (Bernis et al., 1999). In light of other possible variables that could be used to explain menstrual disturbance, future studies should include these factors and possibly provide a more comprehensive outlook of conditions which may influence menstrual problems in young adults.

\section{Conclusions}

A total of 995 female students were selected using stratified random sampling with a proportional allocation technique from July 2004 to May 2005 at the University of Rajshahi, Bangladesh. Multiple logistic regression and stepwise regression were used to detect the effect of anthropometric measures and sociodemographic factors on menstrual disturbances (menstrual pain and irregular menstrual cycles). These statistical tools demonstrated that students who reached menarche earlier, had an earlier birth order, came from higher-income families and had longer duration of menstrual flow were more likely to experience menstrual pain. Students who reached menarche later and had larger
BMI values as well as longer menstrual flow were more likely to experience irregular menstrual cycles.

\section{Conflict of interest}

All authors declare that there are no conflicts of interests in relation to this study. In addition, this research received no specific grant from any institutes, funding agency in the public or commercial sectors.

\section{References}

Adams H.P.J. and Deitch H.R. (2005) Menstrual disorders in the college age female. Pediatric Clinics of North America, 52: 179-197.

Agarwal A. and Venkat A. (2009) Questionnaire study on menstrual disorders in adolescent girls in Singapore. Journal of Pediatric and Adolescent Gynecology, 22: 365-371.

Anai T., Miyazaki F., Tomiyasu T., and Matsuo T. (2001) Risk of irregular menstrual cycles and low peak bone mass during early adulthood associated with age at menarche. Pediatrics International, 43: 483-488.

Anastasakis E., Kingman C.E., Lee C.A., Economides D.L., and Kadir R.A. (2008) Menstrual problems in university students: an electronic mail survey. In Vivo, 22: 617-620.

Balbi C., Musone R., Menditto A., Prisco L.D., Cassese E., D'Ajello M., Ambrosio D., and Cardone A. (2000) Influence of menstrual factors and dietary habits on menstrual pain in adolescence age. European Journal of Obstetrics \& Gynecology and Reproductive Biology, 91: 143-148.

Bernis C., Montero P., and Castro S. (1999) Menstrual pain, menarcheal age and lifestyles in Spanish adolescents. International Journal of Anthropology, 14: 85-97.

Brooks-Gunn J. (1985) The salience and timing of the menstrual flow. Psychosomatic Medicine, 47: 363-371.

Chan Y.H. (2004) Biostatistics 202: logistic regression analysis. Singapore Medical Journal, 45: 149-153.

Chang Y.T. and Chen Y.C. (2009) Study of menstrual attitudes and distress among postmenarcheal female students in Hualien County. Journal of Nursing Research, 17: 20-29.

Chatterjee S. and Hadi A.S. (2006) Regression Analysis by Example, 4th edn. John Wiley, New York.

Chowdhury A.K., Huffman S.L., and Curlin G.T. (1977) Malnutrition menarche and marriage in rural Bangladesh. Social Biology, 24: 316-325.

Chowdhury S., Shahabuddin A.K., Seal A.J., Talukder K.K., Hassan Q., Tomkins A., Costello A., and Talukder M.Q. (2000) Nutritional status and age at menarche in a rural area of Bangladesh. Annals of Human Biology, 27: 249-256.

Di Cintio E., Parazzini F., Tozzi L., Luchini L., Mezzopane R., Marchini M., and Fedele L. (1997) Dietary habits, reproductive and menstrual factors and risk of dysmenorrhoea. European Journal of Epidemiology, 13: 925-930.

El-Gilany A.H., Badawi K., and El-Fedawy S. (2005) Epidemiology of dysmenorrhoea among adolescent students in Mansoura. Eastern Mediterranean Health Journal, 11: 155163.

Farquhar C.M., Roberts H., Okonkwo Q.L., and Stewart A.W. (2009) A pilot survey of the impact of menstrual cycles on adolescent health. Australian and New Zealand Journal of Obstetrics and Gynaecology, 49: 531-536.

Haq M.N. (1984) Age at menarche and the related issue: a pilot study on urban school girls. Journal of Youth and Adolescence, 13: 559-567.

Hirata M., Kumabe K., and Inoue Y. (2002) Relationship between the frequency of menstrual pain and bodyweight in female adolescents. Nippon Koshu Eisei Zasshi, 49: 516-524 (in 
Japanese).

Hossain M.G., Islam S., Aik S., Zaman T.K., and Lestrel P.E. (2010) Age at menarche of university students in Bangladeshi: secular trends and association with adult anthropometric measures and socio-demographic factors. Journal of Biosocial Science, 42: 677-687.

Jahromi M.K., Gaeini A., and Rahimi Z. (2008) Influence of a physical fitness course on menstrual cycle characteristics. Gynecological Endocrinology, 24: 659-662.

Järvelaid M. (2005) The effect of gynecologic age, body mass index and psychosocial environment on menstrual regularity among teenaged females. Acta Obstetricia et Gynecologica Scandinavica, 84: 645-649.

Loto O.M., Adewumi T.A., and Adewuya A.O. (2008) Prevalence and correlates of dysmenorrhea among Nigerian college women. Australian and New Zealand Journal of Obstetrics and Gynaecology, 48: 442-444.

Menard S. (2002) Applied logistic regression analysis, 2nd edn. Sage Publications, Thousand Oaks, CA.

Montero P., Bernis C., Fernandez V., and Castro S. (1996) Influence of body mass index and slimming habits on menstrual pain and cycle irregularity. Journal of Biosocial Science, 28: 315-323.

Nicodemus K.K., Folsom A.R., and Anderson K.E. (2001) Menstrual history and risk of hip fractures in postmenopausal women. The Iowa Women's Health Study. American Journal of Epidemiology, 153: 251-255.

Ogata A. (1979) Age at menarche and marriage in Bangladesh women. Journal of Tropical Medicine and Hygiene, 82: 6874.

Ogunfowokan A.A. and Babatunde O.A. (2010) Management of primary dysmenorrhea by school adolescents in Ile-Ife,
Nigeria. Journal of School Nursing, 26: 131-136.

Ozerdogan N., Sayiner D., Ayranci U., Unsal A., and Giray S. (2009) Prevalence and predictors of dysmenorrhea among students at a university in Turkey. International Journal of Gynecology \& Obstetrics, 107: 39-43.

Polat A., Celik H., Gurates B., Kaya D., Nalbant M., Kavak E., and Hanay F. (2009) Prevalence of primary dysmenorrhea in young adult female university students. Archives of Gynecology and Obstetrics, 279: 527-532.

Riley A.P., Huffman S.L., and Chowdhury A.K. (1989) Age at menarche and postmenarcheal growth in rural Bangladeshi females. Annals of Human Biology, 16: 347-359.

Singh A., Kiran D., Singh H., Nel B., Singh P., and Tiwari P. (2008) Prevalence and severity of dysmenorrhea: a problem related to menstruation, among first and second year female medical students. Indian Journal of Physiology and Pharmacology, 52: 389-397.

Sundell G., Milsom I., and Andersch B. (1990) Factors influencing the prevalence and severity of dysmenorrhoea in young women. British Journal of Obstetrics and Gynaecology, 97: 588-594.

Wei S., Schmidt M.D., Dwyer T., Norman R.J., and Venn A.J. (2009) Obesity and menstrual irregularity: associations with SHBG, testosterone, and insulin. Obesity, 17: 1070-1076.

Weller A. and Weller L. (2002) Menstrual irregularity and menstrual symptoms. Behavioral Medicine, 27: 173-178.

Yamamoto K., Okazaki A., Sakamoto Y., and Funatsu M. (2009) The relationship between premenstrual symptoms, menstrual pain, irregular menstrual cycles, and psychosocial stress among Japanese college students. Journal of Physiological Anthropology, 28: 129-136. 